\title{
HPTLC Chromatographic Polyphenolic Fingerprints of Plant Species from Eastern Europe
}

\author{
Corina Bubueanu ${ }^{1 *}$, Ramona Pavaloiu ${ }^{2}$ \\ ${ }^{1}$ Extractive Biotechnologies Department, National Institute for Chemical-Pharmaceutical R\&D (ICCF-Bucharest), Vitan Road 112, Sector 3, \\ Bucharest, ROMANIA \\ ${ }^{2}$ Organic Synthesis Department, National Institute for Chemical-Pharmaceutical R\&D (ICCF-Bucharest), Vitan Road 112, Sector 3, Bucharest, \\ ROMANIA \\ *Email for Correspondence: corina.bubueanu@yahoo.com
}

\begin{abstract}
Polyphenols are plant secondary metabolites. They are important active principles from medicinal plants and food supplement that contain medicinal plants. Experimental data indicate that polyphenols exhibit biological functions, as protection against oxidative stress and degenerative diseases. For identification of polyphenolic compounds in plants high-performance thin layer chromatography (HPTLC) is one of the simple and accurate method, which provide important information regarding chemical composition. The chromatographic polyphenolic fingerprint of the four species analysed (Allium sativum - garlic- green leaves, Allium ursinum - wild garlic - green leaves, Malus pumila - apple tree - leaves, Pyrus communis - pear tree - leaves) revealed the present of flavonoid glycosides and hydroxycinnamic acids compounds. Because for all the four species for nutritional and therapeutic purpose are used other part of them (garlic and wild garlic- bulbs and apple and pear-fruits) the results obtained can be a first step for superior valorification of hole plant.
\end{abstract}

Key words: chromatographic polyphenolic fingerprint, garlic, wild garlic, apple, pear, leaves

\section{INTRODUCTION}

Polyphenols are plant secondary metabolites. They are important active principles from medicinal plants and food supplement that contain medicinal plants. Are every day part of our diet by fruits and vegetable that we consume because are abundant in plant-derived foods, particularly fruits, seeds and leaves (Petti S and Scully C, 2009).

Polyphenols are compounds with phenolic structural features. The polyphenols group contains sub-groups of phenolic compounds. In plants are present (in the majority) in the form of glycosides. Classification of polyphenols is made by chemical structure, origin and biological function. One of the classification according to the chemical structures of the aglycones comprise phenolic acids (manly benzoic acid and cinnamic acid derivatives), flavonoids (isoflavones, neoflavonoids and chalcones, flavones, flavonols, flavanones and flavanonols, flavanols and proanthocyanidins, anthocyanidins) and polyphenolic amides (Rong Tsao, 2010).

Experimental data indicate that polyphenols exhibit biologilcal functions, as protection against oxidative stress and degenerative diseases. This actions can be attributed to their antioxidant activities. Results of the in vivo and in vitro studies shown that polyphenols have antioxidant and free radical scavenging, anti-atherosclerosis and cardioprotection, neuroprotective, anti-inflammatory, antimutagenic/anticarcinogenic, antiallergic, antidiabetic, contraceptive properties, effects on anti-aging and neurodegenerative diseases, maintenance of gastrointestinal health and effects on digestive enzymes, improvement of endothelium functions, protective effect on immune cell functions regulation of cell cycle progression, modulation of hormonal effects and effect in the treatment of chronic obstructive pulmonary disease (Xiuzhen Han, et al.,2007). 
For identification of polyphenolic compounds in plants, high performance thin layer chromatography (HPTLC) is one of the simple and accurate method, which provide important information regarding chemical composition. HPTLC gives chromatographic fingerprints which are unique to each species.

Since Eastern Europe is the one of most important region for export of medicinal and aromatic plants in Europe, is important to know the chemical composition of plants from that area. Therefore, this study was aimed to investigate the qualitative polyphenolic composition of the plants presented in Table 1.

Table 1: Plant material

\begin{tabular}{|l|l|l|l|}
\hline Latin name & Family & Common name & Part analysed \\
\hline Allium sativum L & Liliaceae & garlic & green leaves \\
\hline Allium ursinum L. & Liliaceae & wild garlic & green leaves \\
\hline Malus pumila Mill. & Rosaceae & apple tree & leaves \\
\hline Pyrus communis L. & Rosaceae & common pear tree & leaves \\
\hline
\end{tabular}

\section{Materials AND Methods}

Chemicals. NP - natural product (Fluka), PEG - polyethylene glycol (Fluka), methanol and ethanol HPLC grade, ethyl acetate, acetic acid, formic acid, distilled water. References substances: luteolin, rutin, caffeic acid, chlorogenic acid, rosmarinic acid, hyperoside, ferulic acid (Sigma Chemical Co., St. Louis, USA).

Sample preparation: the raw material (purchased from the local store) was extracted with ethanol $50 \%(\mathrm{v} / \mathrm{v})$ for 5 minutes, at boiling temperature of the solvent $(1 / 15 \mathrm{~m} / \mathrm{v}$ vegetal material/ solvent rate). After filtration, the extracts were frozen until analysis.

Polyphenols by HPTLC Analysis: was made by the method described in TLC Atlas - Plant Drug Analysis (Wagner, H. and Bladt S. 1996). The characteristic fingerprint profile for polyphenolic compounds was determined by a densitometric HPTLC analysis. 3-4.5 $\mu$ l of the samples and 1-3 $\mu 1$ of references substances $\left(10^{-3} \mathrm{M}\right.$ luteolin, caffeic acid, chlorogenic acid, rosmarinic acid, rutin, hyperoside, ferulic acid in ethanol) were loaded as $10 \mathrm{~mm}$ band length in the $20 \times 10$ Silica gel 60F254 TLC plate using Hamilton- Bonaduz, Schweiz syringe and CAMAG LINOMAT 5 instrument. Ethyl acetate-acetic acid-formic acid-water 100:11:11:27 (v/v/v/v) was the mobile phase. Developed plate was dried and derivatized in NP-PEG reagent. With a WinCats and VideoScan software, the fingerprints were evaluated at $366 \mathrm{~nm}$ in fluorescence mode.

\section{RESULTS AND Discussions}

Figure 1 shows chromatographic polyphenolic fingerprint of 1- Allium sativum (green leaf) extract, 2 - Allium ursinum (green leaf) extract, 3 - Malus pumila (leaf) extract, 4 - Pyrus communis (leaf) extract, comparative with references substances 5 luteolin, 6 caffeic acid, 7 chlorogenic acid, 8 rutin, 9 rosmarinic acid, 10 hyperoside, 11 ferulic acid.

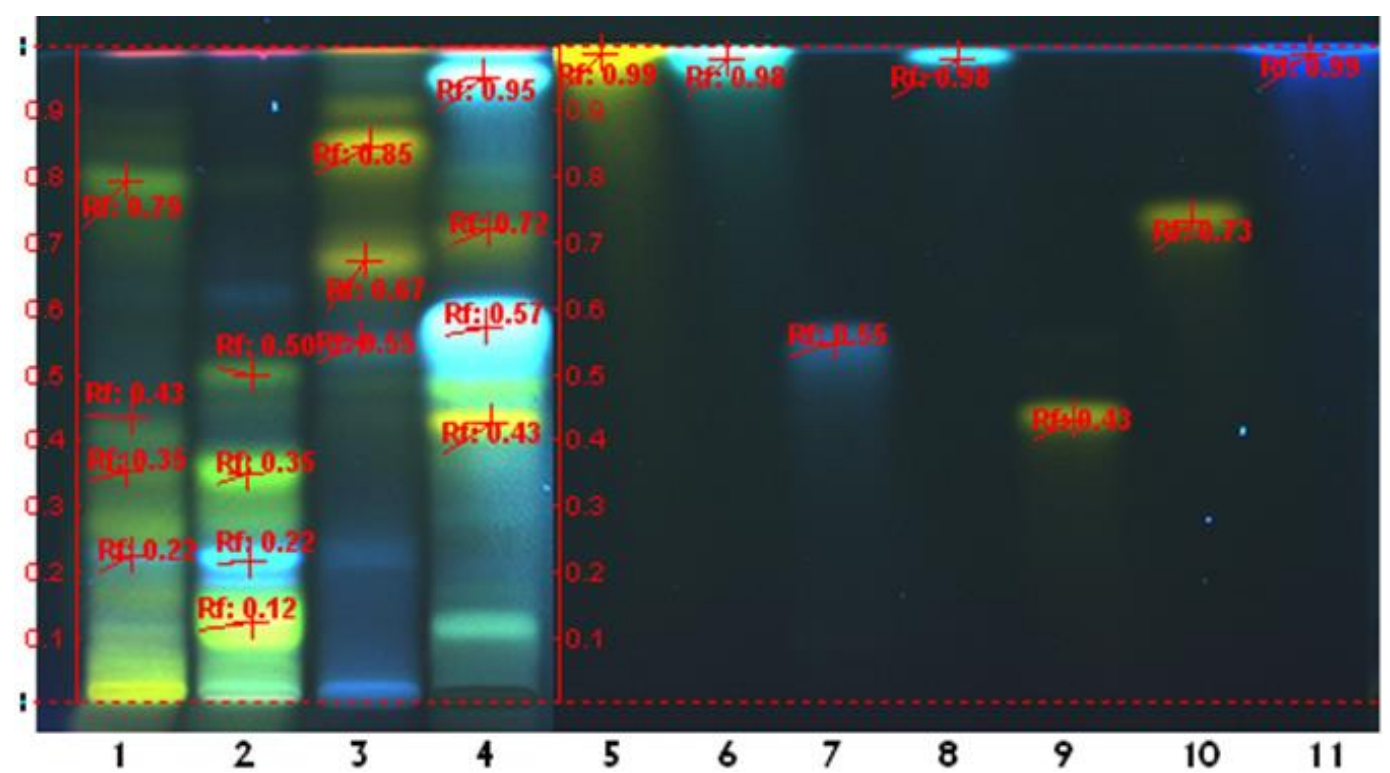

Figure 1: HPTLC phenolic fingerprint of plant species extracts. Track 1 Allium sativum extract; Track 2 Allium ursinum extract; Track 3 Malus pumila (leaf), Track 4 Pyrus communis (leaf) extract, Track 5 luteolin (ref); Track 6 caffeic acid (ref); Track 7 chlorogenic acid (ref); Track 8 rutin (ref); Track 9 rosmarinic acid (ref); Track 10 hyperoside (ref); Track 11 ferulic acid (ref) 
Allium sativum L. (Liliaceae) - garlic - is a herbaceous perennial plant. It is indigenous to Asia, the Mediterranean region, and the Caucasus and the Carpathian Mountains. It was cultivated by approximately 5000-6000 years ago both for nutritional and pharmacological properties. For centuries, it was the only way to combat epidemics of plague. It is now cultivated all over the world. The bulb (formed of several cloves, wrapped in individual membrane) is used as a spice and for medicinal purpose. The sulphur compounds $(82 \%)$ are the most important chemical constituents in garlic bulb. Allin (a sulphur compound) is a natural constituent of garlic bulbs. Allicin is produced during the crushing of garlic cloves, under enzyme reaction of allin. The active principles have antiseptic, bacteriostatic, bactericidal, antispasmodic, carminative, choleretic, diuretic, expectorant, sedative, lowers cholesterol, tonic, anti-tumor properties (WHO Monograph, 1999; (Pârvu, 1997; Ronald Ross Watson et al., 2014). The total polyphenol content of garlic bulbs is reported as $0.0336 \mathrm{mg}$ catechol/mL and $272.28 \mathrm{mg}$ GAE $100 \mathrm{~g}-1 \mathrm{in}$ dry weight (Svetlana Trifunschi et al., 2015; Liga Priecina and Daina Karlina, 2013).

The polyphenolic fingerprint of garlic leaf extract (Figure 1- Track 1) is characterized by four prominent yellow or orange flavonoid glycosides zones ( $\mathrm{Rf} \sim 0.2-0.8$ ) accompanied by one major blue fluorescent zone (Rf 0.22). Based on color and Rf, the yellow spots are glycoside of quercetin (quercetin-3-O-rutinoside (rutin) - Rf= 0.43 ) (Wagner, H. and Bladt S. 1996).

Allium ursinum L. (Liliaceae) - wild garlic or ramsons - is a herbaceous perennial plant. It is spread in Europe. From wild garlic are used for food and medicinal purpose, leaves and bulbs. The plant has garlic taste. Chemical composition includes phenolic compounds (lectins and flavonoids), sulphur compounds (alliin and isoalliin), carotenoids, volatile compounds. Traditional medicine use wild garlic for hypertension, hematuria, eliminate toxins from the body, eliminate intestinal worms. Research studies report wild garlic as having antioxidant and antifungal properties (Carotenuto A, et al., 1996; J Alexieva,et al., 2014; Najjaa Hanen, et al., 2012; M Pârvu, et al., 2011; Pârvu A.E. et al., 2014, Mariana Lupoae, et al., 2012; Pârvu, 1997).

The chromatographic fingerprint of wild garlic (Figure 1 - Track 2) show a similar TLC pattern to garlic. Three major yellow-orange quercetin glycosides zones ( $\mathrm{Rf} \sim 0.2-0.5$ ) accompanied by one major blue fluorescent zone (Rf 0.22) are distinguished.

Malus pumila Mill from the Rosaceae family is the apple tree. The apple fruit is the one of most known and consumed in the world, because it is available in the market all the year and for nutraceutical properties. All over the world there are cultivated over 10000 apple species. In Eastern Europe is an old saying "an apple per day, keeps the doctor away". The fruits contain water, glucid, organic acids, pectin substances, tannins, vitamins. The fruits are an important source of flavonoids (Ronald Ross Watson et al., 2014). Bark, leaves and flowers have anti-inflammatory and disinfectant property (Pârvu, 1997). Total phenol content in apple fruit variates from red to yellow one, peeled or unpeeled between 75.8-125.4 expressed as mg GAE/100g fresh mass (D. Marinova, et al., 2005). The leaves are reported to have a high composition in polyphenolic compounds with important antioxidant activity (Jia-Le Song et al., 2015).

In track 3 - Malus pumila leaves extract chromatographic fingerprint, are present chlorogenic acid $(\mathrm{Rf}=0.55)$ comparative with reference substance (Track -9) and yellow-orange quercetin glycosides zones ( Rf $\sim 0.6-0.8$ ).

Pyrus communis belonging to Rosaceae family is the pear tree which is cultivated in temperate zones of the world. The fruits are consumed fresh, dried or processed. Bark, leaves, flowers and fruits are used in traditional medicine. The bark is astringent. The active principles from bark have local haemostatic properties by protein precipitation. The leaves have antiseptic, disinfectant, diuretic, sedative and antioxidant properties. Flowers have anti-inflammatory properties, and the fruits have diuretic, astringent, digestion stimulating, antioxidant properties (Gonçalves Fernandol, e $t$ al., 2005; Pârvu, 1997). Total phenolic content in fruits determined by Folin-Ciocalteu method showed value as 11.88 mg GAE/100 g of wet weight (Alessandra Francini and Luca Sebastiani 2013). The polyphenolic compounds that were identified in pear leaf (in a methanol/water extract, obtained in acidified medium by ultrasonication) are ferulic acid, coumaric acid, and rutin. Chlorogenic, caffeic, ferulic, and p-coumaric acids (hydroxycinnamic acids) are major phenolic compounds detected in the pear leaves (Milica M. Fotirić Akšić, et al., 2015).

In our hydroalcoholic extract - Track 4 - (obtained by 5 minutes extraction at boiling temperature of the solvent) there were identified blue fluorescent 5-caffeoyl and 3- caffeoyl ( $\mathrm{Rf} \sim 0.55-0.57$ and dicaffeoyl quinic acids un the upper Rf range ( $\mathrm{Rf} \sim 0.95$ ) and yellow-orange quercetin glycosides zones (quercetin-3-O-rutinoside (rutin) $\mathrm{Rf} \sim 0.43$ and $\mathrm{Rf} \sim 0.72$ ).

\section{CONCLUSION}

For the identification of plants HPTLC fingerprint is an important parameter of herbal drug standardization. The results obtained in this study can be used as a diagnostic tool for identification and determination of quality of Allium sativum and Allium ursinum - green leaves, Malus pumila and Pyrus communis - leaves. Because for all the four species for nutritional and therapeutic purpose are used other part of them (garlic and wild garlic- bulbs and apple and pear - fruits) the results obtained can be a first step for superior valorification of hole plant. 


\section{REFERENCES}

Alexieva J, Mihaylova D, Popova A (2014) - Antioxidant capacity and thin layer chromatography of ethanol extracts of Allium ursinum L. and Allium bulgaricum L. - Scientific Bulletin. Series F. Biotechnologies,

Carotenuto A, De Feo V, Fattorusso E, Lanzotti V, Magno S, Cicala C. (1996) The flavonoids of Allium ursinum. Phytochemistry. Feb;41(2):531-6.

Francini Alessandra and Sebastiani Luca (2013) Phenolic Compounds in Apple (Malus x domestica Borkh.): Compounds Characterization and Stability during Postharvest and after Processing Antioxidants, 2, 181-193;

Gonçalves Fernandol, Batista Sandra, Guiné, Raquel, Barroca Maria João, Pérez Maria Dolores, San Jose Maria Luisa, Ferreira, Dulcineia (2005) Sun-dried pears: phenolic compounds and antioxidant activity $7^{\circ}$ Encontro de Química dos Alimentos, 1316 , Viseu

Jia-Le Song, Kai Zhu, Xia Feng, Xin Zhao (2015) Protective effect Malus pumila Mill leaf polyphenols in reserpine-induced gastric ulcer in mice J Korean Soc Appl Biol Chem 58(2):249-256)

Lupoae Mariana, Dinică Rodica, Furdui Bianca, Lupoae Paul (2012) - Study on the content of active principles of some native plants with effect in making the stability and thermal resitance to fried sunflower oil Academy of Romanian Scientists Annals - Series on Biological Sciences, Vol. 1, No. 2

Marinova D. , Ribarova F., Atanassova M. (2005) Total phenolics and total flavonoids in bulgarian fruits and vegetables Journal of the University of Chemical Technology and Metallurgy, 40, 3, 255-260

Milica M. Fotirić Akšić; Dragana Č. Dabić; Uroš M. Gašić; Gordan N. Zec; Todor B. Vulić; Živoslav Lj. Tešić; Maja M. Natić (2015) Polyphenolic Profile of Pear Leaves with Different Resistance to Pear Psylla (Cacopsylla pyri) Journal of agricultural and food chemistry, 63 (34), 7476-7486

Najjaa Hanen, Sami Fattouch, Emna Ammar and Mohamed Neffati (2012). Allium Species, Ancient Health Food for the Future?, Scientific, Health and Social Aspects of the Food Industry, Dr. Benjamin Valdez (Ed.), ISBN: 978-953-307-916-5,

Pârvu Constantin, 1997. Universul plantelor Mica enciclopedie - Ed. Enciclopedica, Bucuresti

Pârvu M, Pârvu AE , Vlase L, Rosca-Casian O, Pârvu O (2011) Antifungal properties of Allium ursinum L. ethanol extract J. Med. Plants Res 5 (10), 2041-2046

Pârvu, A., Cătoi, F., Deelawar, S., Sarup, D., \& Pârvu, M. (2014). Anti-Inflammatory Effect of Allium ursinum. Notulae Scientia Biologicae, 6(1), 20-26.

Petti S, Scully C. (2009) Polyphenols, oral health and disease: A review. J Dent ;37(6):413-23).

Priecina Liga and Karlina Daina (2013) Total Polyphenol, Flavonoid Content and Antiradical Activity of Celery, Dill, Parsley, Onion and Garlic Dried in Conventive and Microwave-Vacuum Dryers 2013 2nd International Conference on Nutrition and Food Sciences IPCBEE vol.53

Rong Tsao (2010), Chemistry and Biochemistry of Dietary Polyphenols, Nutrients, 2, 1231-1246

Trifunschi Svetlana, Munteanu Melania Florina, Agotici Vlad, Pintea Simona, Gligor Ramona (2015) Determination of Flavonoid and Polyphenol Compounds in Viscum Album and Allium Sativum Extracts International Current Pharmaceutical Journal, 4(5): $382-385$

Wagner, H. and Bladt S., (1996). Plant Drug Analysis, A thin layer chromatography atlas. Springer, New York

Watson Ronald Ross, Victor R. Preedy, Sherma Zibadi (2014) Polyphenols in Human Health and Disease, vol. 1, Academic Press, Elsevier, ISBN - 978-0-12-398471-5

WHO Monograph, 1999, vol. 1

Xiuzhen Han, Tao Shen and Hongxiang Lou (2007) Dietary Polyphenols and Their Biological Significance, Int. J. Mol. Sci. 8, 950-988.

--0 -- 